\title{
Ovulation Induction, Pregnancy and Delivery in a Patient with Partial Hypopituitarism due to Lymphocystic Hypophysitis: A Case Report.
}

\author{
Ezechi OC, Ezeobi PM, Nwokoro CA ${ }^{1}$ \\ Nigerian Institute of Medical Research, Yaba Lagos Nigeria and \\ Havana Specialist Hospital, Surulere Lagos, Nigeria?
}

\begin{abstract}
Lymphocystic hypophysitis is an unusual autoimmune disease that causes partial or total hypopituitarism and often associated with chronic anovulation. We report a case of ovulation induction, uneventful pregnancy and vaginal delivery in one of our patient with lymphocystic hypophysitis.
\end{abstract}

Key words: Lymphocystic hypophysitis, chronic anovulation and ovulation induction.

\section{Introduction}

The classical studies of Sheehan have shown that the pituitary gland is very vulnerable during pregnancy and puerperium. ${ }^{1}$ This vulnerability may lead to partial or even total hypopituitarism. Unlike in hypopituitarism due to Sheehan's syndrome, that due to lymphocystic hypophysitis may or may not follow pregnancy, or overt postpartum haemorrhage., ${ }^{2,3}$

Lymphocystic hypophysitis $(\mathrm{LH})$ is a rare pituitary gland inflammatory disease of suspected autoimmune aetiology. ${ }^{2,3,4,5,6,7,8,9}$ Most of the cases occur in young women during pregnancy or the first postpartum year. ${ }^{3,4,5,6}$ It presents with varying degrees of hypopituitarism and often in association with autoimmune diseases. In this syndrome, in the early stage a mass lesion is often seen on the MRI or CT scan which when biopsied consist of lymphocystic infiltration. ${ }^{2,3}$ The mass being inflammatory in origin later disappears. The clinical feature is that of panhypopituitarism or in most cases partial hypopituitarism or isolated deficiency. ${ }^{2,3,6,7}$ This includes amenorrhea, infertility, weakness, cold intolerance, fever, confusion, nausea and vomiting, diarrhea, hypotension and hyperkalemia.
We report a case of a Nigerian woman with partial hypopituitarism secondary to LH in whom a successful ovulation induction was followed by an uneventful pregnancy of a healthy baby following misoprostol induction of labour at term.

\section{Case}

A 39-year-old lady was referred to our infertility clinic from the hospital's medical unit for management of infertility. She was on treatment for hypothyroidism and cortisol deficiency secondary to LH. She was a multiparae, Para $2+1$ all females. Her last delivery 7 years ago was uneventful. She has suffered LH during her last delivery. There was no history of postpartum haemorrhage. She breast-fed her baby for six months. She had repeated admissions for unexplained weakness, fatigue, fever, nausea and vomiting and diarrhea since her last delivery. Because of this her senior sister residing in London invited her for further evaluation in London, where she was diagnosed to have pituitary hypothyroidism and cortisol deficiency due to lymphocystic hypophysitis. She was placed on replacement therapy with hydrocortisone and thyroxine and following, which she recovered. Her follow up since

Correspondence

Dr. Oliver C. Ezechi, MPA, MPH, FWACS, FMCOG, MNIM

PO Box No. 488, Surulere Lagos, Nigeria

Email:oezechi@yahoo.co.uk 
she came back has been in our medical unit from where she was referred to us.

On evaluation at the infertility clinic, she was on hydrocortisone (20mg daily in divided doses) and $\mathrm{L}-$ thyroxine $0.1 \mathrm{mg}$ daily. Clinical examination, routine serum biochemistry was normal. Endocrinological evaluation showed ACTH, TSH deficiency, low FSH, LH and progesterone with normal prolactin level. Semen analysis, tubal patency test were essentially normal. Folliculometry and 21day progesterone assay confirmed anovulation as the possible cause of her infertility. Ovulation induction was initiated with pergonal (human follicle stimulating hormone 75IU/ human luteinising hormone 75IU) and choriegon(human chorionic gonadotrophin 5,000IU). Luteal phase support was given with micronised progesterone $300 \mathrm{mg}$ twice daily. Therapy was successful in the third cycle. Depot progesterone $250 \mathrm{mg}$ IM was given weekly until the $13^{\text {th }}$ week. Early scan confirmed a single intrauterine pregnancy at 6 weeks gestation. She was maintained on the prepregnancy doses of thyroxine and hydrocortisone because hormone assay at 12 week showed normal free thyroxine and cortisol levels.

During the antenatal period she was seen fort nightly until 34weeks and thereafter one weekly till delivery. Antenatal screening was performed according to the hospital protocol. Ultrasound scan, serum biochemistry, free thyroxine hormones were repeated at 28, 32 and 36 weeks and they remained normal. She was also asked to keep fetal movement charts from 28 weeks, which was inspected at every visit.

At 38 weeks, ultra sound scan results showed a mild Oligohydraminos, non stress test showed a reactive fetus. Labour was thus induced with misoprostol 100 microgram. She progressed to full cervical dilatation after 8 hours in labour. She had a vacuum delivery of a live male baby birth weight $3.6 \mathrm{~kg}$ and Apgar score of 7 and 9 at the first and the fifth minutes. During the labour period she was on intravenous hydrocortisone $200 \mathrm{mg}$ stat and then 6hourly until delivery. She had bilateral tubal ligation by modified Pomeroy technique on the first day postpartum. Postpartum period was uneventful. She was referred back to the medical unit for continued care.

\section{Comment}

Lympocystic hypophysitis is an uncommon disorder with a striking female predilection and is related to pregnancy in about $70 \%$ of affected women. ${ }^{2,3}$ The cause is unknown, but the finding of anti-pituitary antibodies in some patients and its association to other autoimmune diseases, mainly thyroiditis, suggests an immune origin. ${ }^{2,3,4}$ In our patient, the beginning of the picture during pregnancy/puerperium is similar to other reported cases elsewhere. ${ }^{4,5,6,7}$, but distinct from cases reported by Garcia-Miguel et $\mathrm{al}^{2}$ and Van Havenberg et $\mathrm{al}^{8}$ occurring outside pregnancy.

Only one case of ovulation induction in a woman with LH had been reported, to the best of our knowledge ${ }^{2}$. Several authors advise the addition of GH to classical treatment with $\mathrm{hMG} / \mathrm{hCG}$ in "poor responders" or GHdeficient patients, ${ }^{2,9}$ but this is controversial. In this patient we used FSH/LH with HCG for ovulation induction. We did not add growth hormone because there was no evidence of growth hormone deficiency, more so we were able to achieve ovulation in the first cycle and pregnancy in the third cycle treatment was used.

The natural history of $\mathrm{LH}$, as well as the influence of further pregnancies on it, is unclear ${ }^{2,4,6}$. There is a close association between pregnancy and the initial occurrence of this disease, so the possibility of deterioration during subsequent pregnancy was a matter of concern to us, we thus counseled her on a permanent contraception. She consented and had bilateral tubal ligation by modified Pomeroy technique. The course of the pregnancy was normal, as could be expected, because replacement therapy with close monitoring was provided ${ }^{2,4,5,6,7}$. Delivery of the baby was decided on the $38^{\text {th }}$ week, because of mild oligohydraminos.

Labor induction with misoprostol was chosen because of its efficacy and safety and more so oxytocin should be avoided in patients like ours because of the risk of water intoxication. ${ }^{10,11}$ A strict fluid balance, avoiding water generating solutions, was necessary, dextrose in saline being the choice. ${ }^{10}$

Corticosteroid supplementation should be increased for any patient being treated for chronic hypoadrenocorticism who undergoes a surgical procedure to prevent possible adrenal crisis., ${ }^{2,3}$ The degree of perioperative stress determines the dose and duration of therapy. Recommendations for perioperative steroid supplementation vary from author to author. ${ }^{2,4,5}$ For minor surgery IV hydrocortisone 25 $\mathrm{mg}$ preoperatively and $50 \mathrm{mg}$ intraoperatively is frequently recommended to supplement their daily prescription. For major surgery hydrocortisone $25 \mathrm{mg}$ preoperatively and $100 \mathrm{mg}$ intraoperatively or dexamethasone $0.75 \mathrm{mg}$ preoperatively and $3 \mathrm{mg}$ intraoperatively are recommended. ${ }^{12,13}$ In this patient, we used IV hydrocortisone $100 \mathrm{mg}$ statum then sixhourly. Oral treatment was resumed after delivery.

Our patient had partial panhypopituitarism evidenced by the low gonadotrophin and normal growth hormone 
levels. Pregestational hormone replacement therapy was maintained, and she did not need adjustment in L-thyroxine and hydrocortisone level during pregnancy because repeated investigations showed normal hormone values.

In conclusion, we reported a case of ovulation induction in a woman with chronic anovulation, cortisol deficiency and hypothyroidism secondary to LH. The patient ran a course similar to that of other reported cases of hypopituitarism due to LH. Therefore a history of LH should not be considered a contraindication to pregnancy.

\section{References}

1. Sheehan HL, Murdoch R. Postpartum necrosis of the pituitary gland: pathological and clinical aspects. Journal of Obstetrics and Gynaecology of British Empire 1938; 45: 456-489.

2. Garcia-Miguel FJ, Martin-Vicente V, Martin-Perez M, Crespo E, Alsina FJ, San Jose JA. Ovulation induction and caesarean delivery after panhypopituitarism secondary to Lympocystic Hypophysitis. The Internet Journal of Obstetrics and Gynaecology 2000; v01.n01. Available at http:/www.ispub.com/internet journal of obstetrics and gynaecology

3. De Swiet M. Diseases of the pituitary and adrenal gland. In de Swiet M(ed), Medical disorders in obstetric practice. Third edition. London, Blackwell science, 1996, 492-493.

4. Brandes JC, Cerletty JM. Pregnancy in lymphocystic hypophysitis: case report and review. Wis Med J 1989; 88:29-32.

5. Jensen MD, Handwerger BS, Scheithauer BW, Carpenter PC, Mirakian R, Banks PM.
Lymphocystic hypophysitis with isolated corticotropin deficiency. Ann Intern Med 1986; 105:200-3.

6. McCutcheon IE, Oldfield EH. Lymphocystic adenohypophysitis presenting as infertility. Case report. J Neurosurg 1991; 74:821-6.

7. Tsur A, Leibowitz G, Samueloff A, Gross DJ. Successful pregnancy in a patient with preexisting lymphocystic hypophysitis. Acta Obstet Gynecol Scand 1996; 75:772-4.

8. Van Havenberg T, Robberecht W, Wilms G, Van Calenberg F, Goffin J, Bouillon R, et al. Lymphocystic infundibulohypophysitis presenting in the postpartum period: case report. Surg Neurol 1996; 46:280-4.

9. Blumenfeld Z, Amit T. The role of growth hormone in ovulation induction. Ann Intern Med 1994; 26:249-54.

10. Paech MJ. Convulsions in a healthy parturient due to intrapartum water intoxication. International Journal of Obstetric Anesthesia 1998; 7:59-61.

11. Ezechi OC, Kalu BKE, Njokanma FO, Nwokoro CA, Okeke GCE. Vaginal misoprostol induction of labour: a Nigerian hospital experience. Journal of Obstetrics and Gynaecology 2004;24( 3):239242

12. Ober KP. Endocrinology and Metabolism Clinics of North America. Philadelphia: WB. Saunders Co., 1993; 101-107.

13. Stoelting RK, Dierdorf SF. Endocrine Disease. In: Stoelting RK, Dierdorf SF (eds.), Anesthesia and co-existing disease. New York. Churchill Livingstone, Inc.1993; 339-75. 